\title{
In Response: The Usefulness of Neutrality
}

Paul A. Dewald, MD

St. Louis University School of Medicine

Follow this and additional works at: https://jdc.jefferson.edu/jeffjpsychiatry

Part of the Psychiatry Commons

Let us know how access to this document benefits you

\section{Recommended Citation}

Dewald, MD, Paul A. (1988) "In Response: The Usefulness of Neutrality," Jefferson Journal of Psychiatry. Vol. 6 : Iss. 1 , Article 11.

DOI: https://doi.org/10.29046/JJP.006.1.010

Available at: https://jdc.jefferson.edu/jeffjpsychiatry/vol6/iss1/11

This Article is brought to you for free and open access by the Jefferson Digital Commons. The Jefferson Digital Commons is a service of Thomas Jefferson University's Center for Teaching and Learning (CTL). The Commons is a showcase for Jefferson books and journals, peer-reviewed scholarly publications, unique historical collections from the University archives, and teaching tools. The Jefferson Digital Commons allows researchers and interested readers anywhere in the world to learn about and keep up to date with Jefferson scholarship. This article has been accepted for inclusion in Jefferson Journal of Psychiatry by an authorized administrator of the Jefferson Digital Commons. For more information, please contact: JeffersonDigitalCommons@jefferson.edu. 


\title{
In Response
}

\section{The Usefulness of Neutrality}

\author{
Paul A. Dewald, M.D.
}

The term "neutrality" as used in psychoanalysis has multiple meanings, each carrying major emotional significance. In that sense "neutrality" is a term which evokes the metaphor of the "Six Blind Men and the Elephant."

In her paper, “The Usefulness of Neutrality," Julia Jones Zawatsky uses the term to express a variety of issues related to a complex and difficult clinical situation. Neutrality includes the therapist taking an equidistant position from the various forces involved in the compromise formation used to solve psychic conflict. She also uses the term to acknowledge the multiple facets of the therapist's conscious and unconscious instinctual life, and responsiveness to patients, as well as the capacity to observe and acknowledge one's own countertransferences. The term describes a therapeutic position serving to understand the dynamic processes involved in a patient's symptomatic behavior, and to recognize that no matter how distressing or painful a patient's behavior may be, it still serves a significant unconscious psychological function. The author contrasts neutral therapeutic behavior and understanding by the therapist and the hospital staff with over-sympathetic, seductive or gratifying patterns and with the assumption of responsibility for the patient's distress, as well as for making progress.

The major thesis of Dr. Zawatsky's interesting case presentation involves recognition that her countertransference-inspired efforts to modify the patient's behavior and alleviate pain and suffering while accepting responsibility for it, ultimately led to a therapeutic stalemate. From a "newly found neutral position" she was able to recognize more clearly and appropriately the meanings of the patient's psychopathology. This led to a more successfully integrated therapeutic approach, which in turn resulted in clinical progress not previously possible. This form of "neutrality" should be part of every therapeutic endeavor, offering a value-free conceptually-organized observational stance seeking to unravel the various levels of dynamic unconscious conflict and their manifestations in manifest conscious derivative behaviors.

However, neutrality is a means and not an end, and as such, what one does with the insights obtained from the objective participant-observer position is a

Paul A. Dewald, M.D. is a supervising and training analyst of the St. Louis Psychoanalytic Institute and Clinical Professor of Psychiatry at the St. Louis University School of Medicine. 
function of the nature and goals of the psychotherapy being undertaken. The therapist's "neutrality" vis-a-vis the patient's transferences and the judicious use of abstinence in order to activate previously dormant or unconscious psychic conflict, is a therapeutic tool appropriate to the psychoanalytically oriented psychotherapies, particularly in classical psychoanalysis. More supportive forms of psychotherapy, however, such as behavior modification, analytically oriented supportive treatment, group processes, individual forms of psychotherapy based on imitation of and identification with the therapist, imply a departure from the neutral position in the therapeutic role. In such instances, understanding of the meanings of the patient's psychopathology and suffering should be based upon the objective value-free neutral observation of the patient's behavior patterns and an understanding of his psychopathology. How that understanding is applied in a therapeutic process is a highly variable activity, which is based upon a therapeutic strategy and a plan to achieve the goals which are set.

Neutrality is often conceived of as antithetical to empathy, but no mutual contradiction exists. The neutral therapist makes use of empathic capacity for understanding intrapsychic processes within the patient, then reverts to a neutral position of therapeutic integration, understanding, decision making and relatively value-free intervention based upon a therapeutic plan.

In some of the non-analytic forms of therapy described above, the understanding achieved by the therapist may come from an empathic as well as neutral value-free observational and theoretical set, whereas the application of that understanding to the therapeutic process may involve significant departures from a value-free or neutral therapeutic stance.

This topic is one to which highly emotional and "non-neutral" responses among therapists are common. Case presentations such as Dr. Zawatsky's and other detailed therapeutic protocols can help in elucidating the multiple meanings which are unfortunately condensed and projected upon that innocuous-sounding word. 